\title{
Construíndo unha lingua, unha literatura e unha patria: Da importancia da produción rosaliana no debate lingüístico decimonónico
}

\author{
Diego Pardo Amado \\ Universidade da Coruña
}

\begin{abstract}
Resumo:
O debate lingüístico que o século XIX galego rexistra permitiu a creación dun modelo culto de lingua, longo e custoso proceso que se prolonga durante o século XX. A produción poética en galego de Rosalía de Castro vai ocupar un lugar central en dita polémica, traendo á tona cuestións de índole política e cultural. Coa intención de pórmos nun primeiro plano os postulados lingüísticos da autora de Cantares gallegos, analizamos nesta colaboración a importancia que o idioma de Galiza significou para a escritora, así como o debate lingüístico que a súa obra alimentou.
\end{abstract}

Palabras chave:

Rosalía de Castro, modelo culto de lingua, crítica literaria, debate lingüístico.

\begin{abstract}
:
The linguistic debate of the Galician 19th century made the creation of a high model of Galician language possible, a long and difficult process extended during the 20th century. Rosalia's Galician poetry will be very important in that polemic, emphasizing topics of political and cultural nature. With the intention of stressing the linguistic postulates of Rosalia of Castro, in this article we will analyze the importance of Galician language for the writer, as well as the lingüistic debate that her work came alive.
\end{abstract}

Key words:

Rosalia of Castro, high model of language, literary critique, lingüistic debate.

\section{Introdución: Rosalía de Castro, avezada coñecedora do idioma}

Cando, á idade de vinte e seis anos, Rosalía de Castro publica Cantares gallegos (1863), xa viran a luz dous poemarios da súa autoría, o mesmo número de novelas, un texto de carácter ensaístico e poemas soltos ${ }^{1}$, ao que debéramos sumar os versos

1 Publicara os libros de poemas La flor (1857) e A mi madre (1863); as novelas La hija del mar (1859) e Flavio (1861), para alén do breve ensaio Lieders (1858); o poema "Lágrima triste en mi dolor vertida", incluído na Corona fúnebre (1859) composta na honra de Aurelio Aguirre, e mais os poemas contidos no Álbum de caridad (1862). 
que na súa adolescencia compuxo, certamente destruídos por lles non outorgar a excelencia de que acaso xa estivesen provistos.

Trinta e cinco anos após a publicación do que merece o título de primeiro monumento lírico das letras galegas do século XIX -referímonos ao poema "A Alborada", de Pastor Díaz-, a obra de Rosalía de Castro eríxese como a consagradora dun movemento cultural que aínda non achara a forza necesaria para se consolidar, impulsando creacións xeniais cuxa xénese debe ser inequivocamente procurada neste poemario e nesta autora, xa que, como a crítica máis tarde xulgará, os escritores anteriores carecían da súa forza e personalidade poética.

Imbuído do crecente espírito patriótico, Cantares gallegos convértese no primeiro libro integramente escrito en galego no novo período. É tal o entusiasmo que a obra xera, como teremos ocasión de comprobar, que a súa difusión traspasa as nosas fronteiras e posibilita unha segunda edición, a única de toda a produción rosaliana de que a escritora é testemuña ${ }^{2}$. Representa o estímulo necesario e tamén a referencia fundacional que todo movemento cultural con anhelos de perduración exixe, xa que é simultaneamente punto de chegada e de partida, non só excepcional pola sublimación artística acadada, mais tamén admirábel polo papel que cumpre na recuperación do galego como lingua literaria, proceso que se completa coa publicación de Follas Novas (1880).

Non é a cuestión idiomática asunto menor, xa que Rosalía será fiel á lingua de noso ao longo de toda a súa vida, determinada desde ben cedo a restituír o prestixio que lle fora usurpado. Así, se repararmos nas súas colaboracións no Album de caridad $(1862)^{3}$, comprobaremos que é a única escritora que utiliza o galego, -maioritariamente por certo-, á diferenza das outras autoras presentes no volume. No propósito en que se embarca, de capital transcendencia para un proxecto rexenerativo de orixe e ámbito urbanos (Freixeiro / Sánchez / Sanmartín 2005: 55), non debemos obviar a importancia que dun punto de vista lingüístico cumpre o feito de os seus primeiros anos de vida transcorreren baixo os ceos de Ortoño e Padrón, circunstancia que a converterá en grande coñecedora do idioma. A predilección que sempre manifestou por aquelas paisaxes significa a alianza íntima coa nación, a asimiliación da nosa cultura popular e mais a identificación plena coa lingua de Galiza, nunha aprendizaxe en que o contacto co campesiñado foi decisivo:

2 En 1872 sae do prelo a 2. ${ }^{a}$ edición de Cantares gallegos, a cargo da Imprenta Rivadeneyra (Madrid), cun total de 35 poemas.

3 Rosalía participa no volume cos poemas “¡Mi madre!”, “Adios que eu voume”, "Castilla”, "O caravel negro", “A romaría da Barca” e “iTerra, a miña!”. Véxase López Cortón J. P. (ed.) (1862). 
Mais naide ten menos qu'eu teño as grandes cualidades que son precisas prá levar á cabo obra tan dificile, anque naide tampouco se pudo achar animado d'un mais bon deseo, prá cantar as bellezas da nosa terra n'aquel dialecto soave e mimoso, que queren facer barbaro os que non saben que aventaxa ás demais linguas en doçura e armonia. Por esto, inda achándome debil en forzas e n'abendo deprendido en mais escola qu'á d'os nosos probes aldeans, guiada solo por aqueles cantares, aquelas palabras cariñosas e aqueles xiros nunca olvidados que tan doçemente resoaron nos meus oidos desd'á cuna, e que foran recollidos po-lo meu corazon como harencia propia, atrevinme á escribir estos cantares, esforzándome en dar á conocer como algunhas d'as nosas poéticas costumes inda conservan certa frescura patriarcal e primitiva, e com'ó noso dialecto doçe e sonoro é tan aproposito com'ó pirmeiro para toda clase de versificacion (Castro, R. de 1863: 5-6).

\section{As primeiras críticas: Cantares gallegos (1863)}

Como é sabido, a consideración do galego durante o século XIX é de absoluto desprestixio (Hermida 1992a: 49-54), feito que directamente repercute no ritmo do proceso rexenerativo iniciado. Neste sentido, Carvalho Calero (1979a: 33-34) ten sinalado que, aínda que a celebración dos Xogos Florais da Coruña procuraba impulsar o cultivo literario do galego, existía unha masa de opinión ilustrada que se tería oposto a calquera empresa que non considerase a lingua castelá, nas palabras do crítico ferrolán.

Neste contexto hostil, Rosalía de Castro forma parte da minoría que confía na restauración cultural e idiomática, convicción que xa suxerimos arriba ao salientarmos que foi a única escritora que participou no Álbum de caridad con composicións en galego, aposta pola lingua que acha en Cantares gallegos o impulso máis sólido e tamén o máis decisivo para o futuro da mesma. Así, a produción rosaliana foi central no debate lingüístico decimonónico, artellado arredor de cuestións de natureza filolóxica, mais sen deixar de se interesar polo futuro do galego e mais pola problemática derivada do seu incipiente cultivo literario ${ }^{4}$, como tamén revelan as seguintes palabras de Murguía:

¿Hizo bien en emplear el gallego en un libro [Cantares gallegos] destinado a describir los paisajes, las cotumbres, en una palabra, las cosas de Galicia y de sus gentes? Hay quien lo duda, por creer la cosa hija de un pasajero capricho y no de un movimiento reflexivo; porque se piensa que el empleo de los dialectos es un retroceso; porque se teme a cuanto habla a la provincia de

4 Véxase Saco e Arce (1876); Manuel Murguía (1879); Balbín de Unquera (1880). 
lo que ha perdido, y en fin, porque hay muchos que no les importa sacrificar al Moloch moderno, la centralización, estas pequeñas agrupaciones al parecer tan insignificantes y estériles, que teniendo una historia, una ley, una lengua y una raza, conservan todavía todos los elementos constitutivos de un estado. ¡Además se habla de la patria!... (Murguía, 1940: 143-144).

O primeiro documento crítico sobre esta obra ${ }^{5}$ debémolo a José López de la Vega, integrado nos estudos que á literatura galega e portuguesa consagra en Galicia. Revista universal de este reino. Na liña das cuestións preliminares sumariamente apuntadas nas primeiras liñas do noso artigo, López de la Vega celebra a conquista que a publicación do poemario simboliza para as letras galegas, aínda sen a perspectiva suficiente para se aventurar a ditaminar que aquela obra significaba a culminación do movemento e a súa expresión máis perfecta, como máis tarde ficaría folgadamente demostrado.

De forma ben significativa, a obra de Rosalía de Castro é comparada ás baladas de Vicente Barrantes e ás cancións populares de Trueba -a quen Rosalía alude no ensaio preliminar desta a súa primeira obra no noso idioma-, atribuíndolle á escritora galega unha sensibilidade excepcional, non superada pola daqueloutros poetas. $\mathrm{O}$ crítico caracteriza o poemario pola espontaneidade que suxiren as flores arrincadas á natureza, ao tempo que atribúe á man que as recolle calidades tan propias dos poetas románticos. Con efecto, após valorar moi positivamente $A$ mi madre (1863) -canto emocionado pola nai que xa non está-, nota a relación da obra coa do poeta alemán Heinrich Heine, salientando que as composicións do tomo "emulan noblemente en pureza de estilo, en correcta frase gallega, en una sintaxis brillante y en una cadencia armónica" (López de la Vega 1863: 179) as do vate de Düsseldorf.

Importa esta valoración positiva de aspectos de índole formal e estilística porque tacitamente significa o certificado de aptitude da lingua galega, agora en igualdade de condicións con outros idiomas europeos canto á súa materia prima e, por tanto, a xustificación que permite loitar pola súa igualación. Á parte, debemos considerar as dificultades derivadas da ausencia de instrumentos lingüísticos elementais para

5 Non consideramos como tal os anuncios da obra (aínda co libro en prensa), malia o carácter premonitorio das súas palabras: "En vista del mérito de cuantas composiciones gallegas hemos leído de nuestra poetisa Rosalía, no podemos menos de recomendar la adquisición de su nueva obra que no sólo debe ocupar el estante de todo gallego literato, sino que parece llamado ese libro a ser de texto para todo poeta que haya de metrificar en el gallego idioma, y nos atrevemos a decir más y es que muchos de sus cantares han de llegar con el tiempo a popularizarse tanto que ocuparán la memoria hasta de nuestros campesinos, los cuales, acompañándolos a las notas de su música tierna, sentimental y sencillos los entonarán unidos a las cantigas populares que poseen; tal es el carácter que su autora ha sabido imprimirles que viene a ser todo uno su poesía de este género con la poesía popular de nuestra amada Galicia" (Alonso Montero (ed.), 1985: 190). Cfr. cos anuncios contidos na tapa das seis primeiras entregas do Diccionario de escritores gallegos de Manuel Murguía. 
o correcto e común emprego do galego (só a partir de 1863 aparecen os primeiros dicionarios e gramáticas $)^{6}$, circunstancia que a propia Rosalía expón no ensaio que precede Cantares gallegos ${ }^{7}$ :

Foy este o movil principal que m'impeleu á pubricar este libro que, mais que nadie, conoço que necesita á indulxencia de todos. Sin gramática nin regras de ningunha clás, ó lector topará moitas veces faltas d'ortografia, xiros que disoarán ôs oidos d'un purista; pró ô menos, e prá disculpar en algo estes defectos, puxen o mayor coidado en reprodusir ó verdadeiro esprito d'ó noso pobo, e penso qu'o conseguin en algo... si ben de unha maneira débil e froxa. ¡Queira ó ceo qu'outro mais afertunado qu'eu poida describir c'os seus cores verdadeiros os cuadros encantadores que por aquí s'atopan, inda no rincon mais escondido e olvidado, prá qu'asi, ô menos en fama, xa que non en proveito, gane e se vexa c'o respeto e adimiracion merecidas esta infortunada Galicia! (Castro, R. de 1863: 11).

Por seu lado, José María Posada ${ }^{8}$ valora a importancia de ser Galiza elemento basilar de Cantares gallegos (1863) e, sobre todo, a decisión de se escribir no idioma propio. As palabras do cofundador do Faro de Vigo ratifican que o propósito da obra debe moito ao proxecto político a que serve e, por conseguinte, responde tamén a unha clara función social, unha vez que "en todas [as composicións] hay un noble fin; el que debe animar a todo ingenio, que se consagra al penoso ejercicio de mejorar la sociedad" (Posada 1863: 203).

En virtude deste posicionamento, resulta doado comprendermos que se emprenda o combate contra a secular actitude xeneralizada de odio e desprestixio cara á nosa nación, en que o idioma, como signo principal de identidade, resultara maiormente damnificado. Igualmente, sostén Posada, só en "dialecto" galego, cuxo vínculo co país resulta insubstituíbel, poderán ser expresados con exactitude os nosos sentimentos:

Y para que sea más perfecto el retrato de Galicia se expresa en su propio dialecto, dando de este modo una prueba evidente a los que lo desdeñan, sin conocerlo, de que es el habla de la poesía más delicada y armoniosa, el habla de las cantigas de don Alfonso el Sabio, y de las endechas del enamorado Macías (Posada 1863: 203).

6 Cfr. Sánchez Rei (2005: 95-100).

7 Cfr. Lorenzo (1986: 21-22); Véxase tamén Freixeiro / Sánchez / Sanmartín (2005: 60-61).

8 José María Posada Pereira (1817-1886) é o autor de Poesías (1886) e mais de Poesías selectas (1888), tamén cofundador de La Aurora de Galicia (1845) con Francisco Añón e de Faro de Vigo, con Carvajal Pereira. 
Non sorprende a argumentación empregada por este autor, da que achamos prolixas mostras nos textos fundacionais da nosa literatura, cuxa finalidade é xustificar o incipiente movemento cultural e mais a necesaria descolonización lingüística ${ }^{9}$. A centralidade do discurso reside na adxectivación positiva da lingua que se pretende $\operatorname{prestixiar}^{10}$, en contraposición á carencia de refinamento aposta, así como na mención e exaltación de figuras de primeira orde na nosa historia literaria, memorábeis, entre outros froitos, por un excelente uso artístico do galego. Igualmente, Ventura Ruiz Aguilera $^{11}$ xulga que se pode estabelecer unha identificación clara entre cada un dos Cantares e Galiza, escritos "con la vaguedad y dulzura del dialecto de la raza que puebla sus costas, sus valles y sus montañas” (Ruiz 1864: 174), xuízo decote utilizado para expresar a autenticidade da obra, que acha neste aspecto un dos seus argumentos máis rendíbeis ${ }^{12}$. Á vista desta recorrente citación meliorativa, non nos fica dúbida do papel que á produción rosaliana foi asignado, apelando á súa práctica autorial como exhibición da dignidade e versatilidade do galego, única vía de expresión verdadeira se de Galiza se tratar.

Por seu lado, Leandro de Saralegui y Medina ${ }^{13}$ dedica o capítulo VIII de Galicia y sus poetas (1886) á análise da obra de Rosalía de Castro. Os seus primeiros escritos sobre crítica literaria saíran á luz en 1858, reproducidos en diversas ocasións pola

9 Cfr. cos factores de prestixio que sinala Carme Hermida (1992: 92-122): nobreza de orixe, a literatura medieval, primeira lingua, extensión pola península, pai do castelán e da literatura castelá ou o seu parentesco co portugués, entre outros.

10 Véxase Taboada Fernández (1880): "La literatura provinciana que arrancó tan sublimes cantos al trovador Macías, este hermosísimo dialecto, dulce y enamorado como el suspiro de un ángel, armonioso y expresivo como una frase de Rossini, acaba de acoger en su seno la más preciada joya de las galaicas letras".

11 Lembremos que Ventura Ruiz Aguilera (1820-1881) estudou medicina na cidade de Salamanca, onde nacera. En 1844 trasládase a Madrid para se dedicar á literatura e á política, colaborando en publicacións de carácter progresista como La reforma ou La tribuna del pueblo e ocupándose tamén do cargo de director do Museo Arqueolóxico Nacional. Autor de Ecos nacionales (1849 e 1854), Elegías e Leyendas de nochebuena, puxo a poesía ao servizo dos seus ideais político-relixiosos, inspirado polos postulados románticos. É tamén autor do drama Camino de Portugal e da novela El beso de Judas (1860). Téñase en conta que Rosalía inclúe o poema "La gaita gallega" de Ruiz Aguilera xa na 1. a edición de Cantares gallegos (1863), ao que replica con "A gaita gallega, resposta". Tamén Rosalía verterá ao galego poemas deste autor, publicados na 2. edición de Armonías y cantares (1865).

12 A apreciación de Ruiz Aguilera lembra as intencións que Rosalía de Castro expresa no ensaio preliminar de Cantares gallegos (1863), tamén referido por este autor, que sinala a frecuencia de sufixos diminutivos nesta obra como trazo distintivo do noso idioma e o conxunto do libro como recipiente en que se custodia o espírito da fala. Cfr. tamén coas palabras de García Martí (1944: 161): "El hecho de servirse Rosalía del gallego da un perfume campesino a su obra y la acerca más al alma del pueblo".

13 Foi ordenador do Arsenal de Ferrol, intendente de Ferrol e intendente xeral do ministerio da Mariña. É o autor de Estudios sobre la época céltica en Galicia (1867), Estudios sobre Galicia (1888) ou La cuestión obrera en Galicia (1893). 
prensa galega, razón que explicaría que o volume de 1886, redixido vinte e sete anos despois dos escritos que lle serven de base, como el mesmo afirma, non se ocupe da restauradora da literatura galega contemporánea até un capítulo tan avanzado. Segundo este autor, as causas da difusión e aceptación da produción rosaliana radicarían, en primeiro lugar, no carácter esencialmente galego deste poemario, característica de que se había derivar que non fosen plenamente comprendidos fóra das nosas fronteiras, segundo conclúe.

É este "carácter local" ou "sentimento provincial" que inspira o poemario o que asegura a súa gloria, mais tamén o que limita a súa xusta valoración fóra das nosas fronteiras, xuízo de Saralegui que en certa medida nega o carácter universal que a obra si posúe, como o paso dos anos desmostrou. En segundo lugar, a elección dun recipiente poético idóneo, na medida do cantar como forma literaria que máis se adecúa á expresión do sentir galego e que xustifica que non se asentasen na nosa literatura nin o sone bretón nin a saga escandinava. E, por fin, a habilidade da autora para realizar a obra coa sensibilidade coñecida e o suceso acadado, e aínda como demostración das posibilidades expresivas do idioma galego, "revelando toda la riqueza, toda la hermosura, toda la fluidez de nuestro dialecto, tan grato á las musas españolas en el siglo XIII como olvidado y desatendido en épocas posteriores" (Saralegui 1886: 78), contestación empírica ás agresións continuadas que tencionaban erradicar tamén calquera reflexo literario da lingua nacional.

Alén disto, o contexto histórico, pouco considerado á hora de valorar a obra de Rosalía de Castro, é tido en conta por este autor, que repara na adversidade derivada dunha centralización administrativa que tiña comportado o desaparecemento das antigas circunscricións e que implicou tamén a asimilación cultural, ou en palabras de Saralegui, a perda "de nuestras costumbres peculiares, de nuestros hábitos y nuestros caracteres propios" (Saralegui 1886: 83), de modo que o labor de Rosalía, -que, lembremos, ten de recuperar da memoria colectiva cantigas e lendas populares-, resulta meritoso por partida dobre.

\section{A culminación dunha loita lingüística: Follas Novas (1880)}

Malia as innegábeis conquistas lingüísticas acadadas en distintos ámbitos (o galego incrementa a súa presenza pública, existen máis escritores que o cultivan e estudan...), o proceso de substitución polo castelán segue a avanzar, xa sen seguir unha orientación horizontal e selectiva, senón afectando ao conxunto da sociedade galega (Hermida 1992a: 46-47). Manuel Murguía (1833-1923), a quen Vicente Risco definira como unha sorte de síntese do esforzo daquela hoste de patriotas 
galegos que foran os precursores (Risco 1976: 7), testemuñou dita mudanza, da que en máis dunha ocasión chega a se lamentar e a respecto da cal decide actuar ${ }^{14}$.

As avanzadas ideas lingüísticas que o historiador defendeu, -analizadas, entre moitos outros, por Freixeiro, Sánchez e Sanmartín (2005: 63-79)-, constituíron o elemento central das súas reivindicacións. Dada a relevancia que as teorías do historiador compostelán acadan nos círculos literarios e políticos, cumprirá preguntármonos até que punto tamén a súa ideoloxía lingüística inflúe na autora de Follas novas ou en que medida determina a súa decisión de escribir en galego. Porén, resulta imprescindíbel non supeditar a práctica autorial da nosa escritora aos estímulos do esposo, valorándomos Rosalía de Castro como unha intelectual con ideas lingüísticas de seu, capaz de se comprometer co idioma motu proprio. Con todo, isto non implica que o discurso murguiano deixase de ter ecos no posicionamento lingüístico da escritora (como tamén os tivo no caso doutros eruditos), consideración que debe ser realizada con cautela. Da nosa óptica, prodúcese neste sentido un fenómeno similar ao que sobredimensiona o papel de Manuel Murguía como revisor e difusor do traballo literario da poeta, esquecendo que a orientación intelectual practicada foi recíproca, probabelmente tamén nas cuestións referidas ao idioma.

Proxección do impacto que a súa obra poética anterior causara, Follas Novas significa a consolidación definitiva da literatura galega contemporánea. É tamén agora, na óptica de Monteagudo (1999: 361-372), que se produce a institución do galego literario, en coincidencia coa culminación do Rexurdimento. Así, en base a un criterio cronolóxico debemos considerar a recensión "Follas Novas"15, en que este libro é considerado na mesma medida que Cantares gallegos ou mesmo nun nivel superior: "una obra poética que emula, sino escede en mérito, á su otro libro titulado "Cantares gallegos"'. Novamente, recoñécese que ao lado da obra de 1863, Follas Novas pon fin a un período de silencio de varias centurias, curiosamente considerada como pedra basilar no edificio da recuperación cultural, sen eludir o debate político e lingüístico cuxa análise agora nos interesa.

As apreciacións que desta reseña reproducimos abaixo revelan, no plano político, as suspicacias xeradas polos éxitos literarios e culturais do noso primeiro Renacemento, sempre a agocharen a sospeita desmedida de que tras das literaturas rexionais "se oculta siempre el rojo y siniestro espectro del federalismo con todas sus terroríficas consecuencias"; no plano lingüístico, a percepción das dificultades que escribir en galego comportaba do punto de vista fundamentalmente ortográfico, acompañada da proposta de solucións que non excluían a solidariedade lingüística

14 Cfr. Freixeiro 2001: 247-277.

15 Véxase "Follas Novas I" e "Follas Novas II", en Gaceta de Galicia, n. 542 (23-XI-1880) e n. ${ }^{\circ} 543$ (24-XI-1880). 
co portugués, circunstancia que ademais había favorecer a comunicación entre ambas as literaturas:

Por el contrario, la literatura gallega, por su semejanza y analogía con la lusitana, puede ser tildada de facilitar la solución de problemas unitarios: mas nunca de entrañar propósitos y tendencias separatistas. Al ponernos en contacto con Portugal y al aproximarnos á él adelantará en el reloj del tiempo la suspirada hora que con indecible ansiedad esperan, hace largo tiempo, todos los buenos peninsulares. Esto constituye su mayor título de gloria.

Tamén en 1880, Afredo Vicenti ${ }^{16}$ escribe unha interesante recensión con motivo da publicación de Follas Novas, en que se fai eco do que foi un debate de primeira orde arredor das "linguas rexionais", avivado á raíz da publicación desta obra. Así, reproduce a rexa crítica que trae á tona o perigo de as letras rexionais sobrepasaren a fronteira da literatura folclórica e popular ${ }^{17}$, ao tempo que se teme que as linguas tamén chamadas rexionais poidan mesmo comprometer a saúde e integridade de España, enunciación que denota unha nada opaca identificación entre o avance do galego e a súa literatura e mais o afianzamento do movemento político rexionalista.

Aínda que Vicenti asegura non querer entrar en litixios, dedica extenso espazo á clarificación do seu posicionamento, que colide frontalmente co expresado no parágrafo anterior. Na súa opinión, o absurdo ideal "Unam gentem, unam linguam" non conta con posibilidades de triunfo, xa que non é factíbel acabar co idioma de Galiza. Asemade, contrapón a situación político-lingüística de Gales, Bretaña, Provenza e Gascuña á existente en Irlanda, paradigma esta última nación dos conflitos que a imposición idiomática pode comportar; exemplo os dous primeiros países citados da calma política que o respecto cara ás linguas reporta:

A parte de que los dialectos han servido de vehículo á la tradición y de primer instrumento á la poesía, por lo cual con su extirpacion se mutilarian neciamente la historia y la literatura, son además, á nuestro humilde entender, no ya elementos de discordia, pero sí como válvulas de seguridad política, por donde encuentran desahogo y compensación las antiguas razas autónomas que no consienten en ser absorbidas aunque se resignen a vivir sojuzgadas (Vicenti, 1880: 245-246).

16 Cómpre lembrarmos que Alfredo Vicenti (1854-1916) é o autor de Recuerdos 1868-1875 (1876), Orillas del Ulla e Las dos aceras del estrecho de Gibraltar. Ademais, colaborou no Diario de Santiago, La Gaceta de Galicia, El Heraldo Gallego e La ilustración Gallega y Asturiana, entre outros.

17 Cfr. coas similitudes da situación do idioma galego e da súa literatura durante o período franquista. 
Nótese neste punto a diferenza a respecto da situación actual, xa que contrasta co optimismo con que a intelligentsia galega do século XIX contemplaba o futuro do idioma maioritariamente empregado pola poboación (Hermida 1992a: 25), malia se manter a consabida situación de diglosia e desigualdade real. Para alén dunha circunstancia tan alentadora como a que se deriva dun uso masivo do galego, é tamén a existencia dun referente culto alén Miño o que alimenta a esperanza: "Subsistirán, pues, y más que ninguno el gallego, en cuyo favor, amén de las razones expuestas, concurre otra tal y tan poderosa, que ni de intento se pudiera buscar mejor ni más segura garantía" (Vicenti 1880: 247), porque o galego está chamado a servir de intérprete entre Galiza e Portugal, como xa sostivera este autor.

Tamén é salientábel a sagacidade da análise realizada por Alfredo Vicenti, que acerta na formulación de diversas temáticas que se han converter no cerne de polémicas futuras. Ademais, á diferenza das teses pardobazanianas, o autor de Orillas del Ulla comproba a determinación de Follas Novas na consolidación do galego como lingua literaria, xa que nesta obra se ensaian "todas las formas y aptitudes de la lengua neo-latina" (Vicenti 1880: 245), reparando nunha cuestión de envergadura como era a necesidade de o galego ser empregado no tratamento de calquera temática:

Excede éste [Follas Novas] en grandeza de miras, en originalidad y en contextura á todos los productos contemporáneos de la lírica española (Becquer, Campoamor y Nuñez de Arce inclusive); y con la autoridad del nombre no ménos que á favor de la variedad de asuntos, ennoblecerá y fijará sin duda nuestro dialecto, de cuya abundancia, ductilidad y pompa nos ofrece ya clara muestra en la gran oda byroniana consagrada á la memoria del general sir John Moore" (Vicenti 1880: 252).

Por último, diremos que o contributo de Alfredo Vicenti, como no caso da vasta maioría dos intelectuais do século XIX, inclúe un escasamente valorado labor divulgativo de que dá boa conta a conferencia que este autor profire baixo o título "La Literatura gallega en el siglo XIX", acto que se celebra na "Reunión de Artesanos", segundo a noticia que de La Voz de Galicia oferecemos abaixo.

As palabras do artigo revelan a admiración do conferencista a respecto da figura de Rosalía de Castro, ao que se une un inmenso coñecemento da súa biografía e produción literaria completa, todo o cal lle permite retratar cabalmente a autora. Igualmente, destaca a vontade pedagóxica de trasladar á audiencia as informacións necesarias para se producir unha rehabilitación que, xa en 1914, resulta máis que urxente:

El celebrado periodista, después de galana salutación, especialmente para la concurrencia femenina, excusóse por el desencanto que iba a experimentar el 
público, por cuanto el objeto principal, sinó único, de su tema, tenía pensado fuera referente a la gran Rosalía de Castro, pero habiéndose dicho que hablaría de la Literatura en el siglo XIX, veíase obligado, por deferencia a los que habían acudido a escucharle, a tener que adaptarse al tema enunciado y hacer de él su conversación de aquella noche (...). Así, paso tras paso, nos describió nuestra historia literaria actual hasta llegar al año 1863 en el que, con la publicación de los Cantares Gallegos, ese libro inmortal en que resplandece con luz intensísima el génio de la eximia cantora del Sar, se crean una lengua, una literatura y una patria [itálica nosa] ${ }^{18}$.

De especial interese é tamén o discurso que Emilia Pardo Bazán profire pouco despois do falecemento de Rosalía de Castro, nunha velada que o Liceo de Artesáns da Coruña organiza para honrar a memoria da escritora. Nel, a Condesa celebra a publicación de Cantares gallegos (1863), en que Rosalía consegue maxistralmente a expresión lírica dos sentimentos femininos mais, segundo xulga, sen superar ningunha das súas composicións o célebre poema pondaliano "A campana de Anllóns", do escritor tamén aristócrata a quen a coruñesa dedicara un eloxioso capítulo en De mi tierra (1888). Se o primeiro poemario en galego da nosa escritora foi tan contidamente celebrado, peor sorte correrá o segundo. Da fiel reprodución do espírito popular que alberga a primeira das obras, en que predomina o elemento idílico e rústico que dona Emilia considera esencial do verdadeiro carácter do renacemento rexionalista (Pardo Bazán 1888: 33), en Follas Novas Rosalía de Castro desenvolverá unha poesía de cariz metafísico, evolución ben incómoda que certamente provoca que a Condesa sentencie que esta obra se limita a repetir queixumes carentes de orixinalidade (Pardo Bazán 1888: 33). Con efecto, a nosa poeta estaba a quebrantar conscientemente unha noción tacitamente asentada para a literatura galega: o tratamento de temática exclusivamente folclórica; mais Rosalía de Castro concibe o idioma galego na súa dimensión máis universal, opóndose aos límites que pretendían apagar as súas infinitas posibilidades expresivas, actitude que non só foi suscrita pola autora de Los pazos de Ulloa, como Carvalho Calero pondera:

Os Cantares, agás certas incomprensións, foron afervoadamente apraudidos. Aquiles que se intresaban pola literatura e o folk-lore galegos non podían menos de saudar gaiosamente unha obra maxistral no seu xénero. Os que cifraban o seu orgulo en realizar unha obra artística de ares máis universás, e vestían a súa inspiración á moda de París ou de calquera outra capital europea, non tiñan motivos de alarma. Estaba ben que unha fidalguiña provinciá espresase en graciosos versos os sentimentos dos labregos. Rosalía non

18 A recensión, publicada en La Voz de Galicia, é tamén recollida no Boletín da Real Academia Galega, $\mathrm{n}^{\circ} 83,293-295$. 
entraba no seu tarreo. Iles non ían descer a isas miucias. Podía, pois, contar, humilde como era, coa súa magnánima benevolencia. Aprobaron a poesía dos cantares, chea de feminidade e diminutivos. A poesía galega podía continuar desenrolándose por ises camiños. E continuóu. Os seguidores de Rosalía, non xa as mulleres, senón tamén os homes, subraiaron a nota tenra, sentimental, graciosa que constituie o enlevo dos cantares. O mesmo Francisca Herrera Garrido que Valentín Lamas Carvajal. Iste tipo de poesía foi o que recibíu o placet académico (Carvalho Calero 1955: 28-29).

Sen dúbida, este posicionamento xeneralizado pode ser extensíbel ás limitacións que se apoñen ao galego, aceptado sempre que non excedese os límites que tamén eran estabelecidos para a súa literatura. Neste sentido, reveladoras resultan as opinións que Pardo Bazán manifesta a respecto da literatura galega renacente e do movemento político que a acompaña, cuxos integrantes non dubida en designar mediante o sintagma altamente despectivo "jauría regionalista". Advirte sobre o risco que as literaturas rexionais entrañan e, por conseguinte, sobre o inminente perigo que a obra de Rosalía de Castro pode comportar; así mesmo, posterga o Rexurdimento galego á reinaxença catalá, atribuíndo ao despertar cultural galego menor puxanza. Evidentemente, non acredita na literatura galega, certidume que acha o seu correlato na mesma práctica literaria da aristócrata, sempre adscrita ao sistema literario español. De feito, tampouco confía nas posibilidades expresivas do idioma de Galiza, ao que dedica o capítulo titulado “¿Idioma o dialecto?”, contido no volume De mi tierra (1888), con reveladoras reflexións ao respecto ${ }^{19}$. No canto de se sumar á revolución cultural que estaba a ter lugar, enfraquece toda tentativa de restauración baseándose no argumento de que os intelectuais que a protagonizaron non tiñan como lingua primeira o galego. Negar a lexitimidade da defensa do idioma en virtude deste argumento era tanto como impedir que reocupase o lugar que historicamente lle correspondía, xa que, dado o estado de falta de conciencia lingüística, cultural e política das masas populares, só a intelligentsia nacional estaba en disposición de emprender proxecto de tal magnitude. Por esta razón, do noso punto de vista, a máxima de Juan Valdés a que alude Pardo Bazán no seguinte fragmento posúe idéntico significado se a aplicarmos á finalidade procurada polos protagonistas do noso Rexurdimento: ilustrar e enriquecer a lingua que é natural á esmagadora marioría do pobo galego; conseguir que este idioma, a longo prazo, fose escrito por quen tamén o falaba como primeira lingua e evitar o totalitario espallamento do español:

19 Cfr. coas observacións de Sanmartín Rei (2009: 148-149) acerca dos argumentos que Emilia Pardo Bazán esgrime para impedir que o galego se convertese en lingua de prestixio, reinterpretados por Ramón Vilar Ponte no seu discurso de ingreso na Real Academia Galega. 
Hoy el gallego posee, como el catalán y el provenzal, una nueva literatura propia; pero á diferencia de estos dos romances meridionales, el gallego no lo hablan los que lo escriben. Esta anomalía curiosa hace que, para los nacidos en tierra galaica, llegue á ser ambigua y difícil la recta interpretación de aquella elocuente cláusula de Juan Valdés, en su Diálogo de las Lenguas: 'Todos los hombres somos más obligados á ilustrar y enriquecer la lengua que nos es natural y que mamamos en las tetas de nuestras madres, que la que nos es pegadiza y que aprendemos en los libros' (Pardo Bazán 1888: 296).

\section{Conclusión}

Tal e como acabamos de comprobar, existe unha relación directa entre o avance do idioma galego como lingua literaria, a constitución dunha literatura culta e mais os postulados políticos que contemplaban a especificidade galega como eixo central da súa actuación. Directa ou indirectamente, a produción rosaliana ocupa un lugar central en cada un dos debates mencionados, feito que ilustran as palabras de Alfredo Vicenti de que nos apropiamos para titular este escrito. Así, as críticas suscitadas pola publicación de Cantares gallegos e Follas Novas deben ser lidas non só en clave literaria, mais tamén atendéndomos aos outros dous elementos do trinomio formulado, isto é, o político e o lingüístico.

Lonxe do debate ortográfico sobre a lingua galega que o século XIX testemuña, Rosalía de Castro sitúase nun plano máis transcendental para o futuro do idioma, en tanto que imprescindíbel para que aquel puidese ter lugar. A súa produción en galego convértese nun argumento inapelábel contra quen dubida das súas posibilidades expresivas ou sinala a súa condición dialectal como garantía de prostración perpetua. O profundo coñecemento do idioma galego constátase en Cantares gallegos (1863), en que a exhibición da súa dignidade e versatilidade consegue ser o argumento máis rotundo e útil á causa, proceso que se completa coa saída do prelo de Follas Novas (1880).

En definitiva, se ben Rosalía de Castro non participou de forma directa no debate de carácter filolóxico que a prensa decimonónica rexistra, a aproximación que propomos nestas liñas pretende pór en relevo o estímulo que a súa obra tamén significou neste sentido, o vivo debate que provocou (constatábel na análise do torrente crítico que acompaña a publicación da súa poesía en galego), así como o seu carácter determinante na consolidación dun modelo culto para o idioma, punto que sen dúbida dificilmente tería sido acadado sen o impulso que a obra de Rosalía de Castro tamén significou no plano lingüístico. 


\section{Referencias bibliográficas}

Alonso Montero, X. (1985): En torno a Rosalía (Madrid: Ediciones Júcar).

Balbín de Unquera, A. (1880): “Cómo deben cultivarse los dialectos?”, La ilustración gallega y asturiana 28 (8-X-1880), 348-349 [ed. facsimilar Silverio Cañada, 1987].

Carvalho Calero, R. (1955): Sete poetas (Vigo: Galaxia).

Carvalho Calero, R. (1979a): "Castellano y gallego en el 'Álbum de la Caridad", en 1616: Anuario de la Sociedad Española de Literatura General y Comparada, 33-37 (Madrid: Sociedad Española de Literatura General y Comparada).

Carvalho Calero, R. (1979b): Estudos rosalianos. Aspectos da vida e obra de Rosalía de Castro (Vigo: Galaxia).

Carvalho Calero, R. (1981): Historia da literatura galega contemporánea 18081936 (Vigo: Galaxia).

Castro, R. de (1863): "Prólogo de Cantares Gallegos", en López, A. e Pociña A. (ed.) (2005): Poesía galega completa I, 5-11 (Santiago de Compostela: Sotelo Blanco).

Castro, R. de (1880): "Duas palabras d'a autora”, en López, A. / Pociña, A. (ed.) (2004): Poesía galega completa II, 21-28 (Santiago de Compostela: Sotelo Blanco).

Freixeiro Mato, X. R. (1996): Os diminutivos na poesía en galego de Rosalía de Castro, Separata de Scripta philologica in memoriam Manuel Taboada Cid. Tomo II (A Coruña: Edicións Universidade da Coruña).

Freixeiro Mato, X. R. (2001): "Murguía, testemuña do declive do galego e adaíl da súa dignificación", en Congreso sobre Manuel Murguía (Santiago de Compostela: Xunta de Galicia).

Freixeiro Mato, X. R. / Sánchez Rei, X. M. / Sanmartín Rei, G. (2005): A lingua literaria galega no século XIX (A Coruña: Universidade da Coruña).

García Negro, M. P. (1997): "Mulleres e idioma galego: analoxía de dúas subordinacións", Terra e Tempo 6/7, Santiago de Compostela.

García Negro, M. P. (2006): “Estudo introdutorio", en El caballero de las botas azules, Lieders, Las literatas (Santiago de Compostela: Sotelo Blanco Edicións).

García Martí, V. (1944): Rosalía de Castro o el dolor de vivir. (Madrid: Ediciones Aspas). 
Hermida, C. (1992a): Os precursores da normalización. Defensa e reivindicación da lingua galega no rexurdimento (1840-1891) (Vigo: Xerais).

Hermida, C. (1992b): A reivindicación da Lingua Galega no Rexurdimento (18401891). Escolma de textos (Santiago de Compostela: Consello da Cultura Galega).

López, A., Pociña, A. (1993): Rosalía de Castro. Documentación biográfica e bibliográfica crítica. 3 vols. (A Coruña: Fundación Pedro Barrié de la Maza).

López Cortón, J. P. (ed.) (1862): Album de Caridad. Juegos Florales de La Coruña en 1861, seguido de un mosaíco poético de nuestros vates gallegos contemporáneos (A Coruña: Imp. del Hospicio provincial).

López de la Vega J. (1863): "Bibliografía. Cantares gallegos por Rosalía Castro de Murguía”, Galicia. Revista universal de este reino, 16, 179-181; 17, 192194.

Lorenzo, R. (1986): “A lingua literaria na época de Rosalía”, en Actas do Congreso Internacional de estudios sobre Rosalía de Castro e o seu tempo. 15-20 de xullo de 1985. Vol. 3 (Santiago de Compostela: Consello da Cultura Galega / Universidade de Santiago de Compostela).

Monteagudo, H. (1999): Historia social da lingua galega (Vigo: Galaxia).

Murguía, M. (1857): "La flor. Poesías de la señorita Doña Rosalía de Castro", La Iberia, nº 878 (12-V-1857).

Murguía, M. (1862): Diccionario de escritores gallegos (Vigo: Juan Compañel ed.).

Murguía, M. (1879): “¿Desaparecerán los dialectos?”, La ilustración gallega y asturiana 21 (30-VII-1879), 251-252 [ed. facsimilar Silverio Cañada, 1987].

Murguía, M. (1888): Galicia (Barcelona: Establecimiento Tipográfico-Editorial de Daniel Cortezo y $\left.\mathrm{C}^{\mathrm{a}}\right)$.

Murguía, M. (1891): “Discurso no banquete rexionalista de Tuy”, La patria gallega $7-8$.

Murguía, M. (1896a): “Murguía y la Pardo Bazán” (La Voz de Galicia, 29-VIII1896) en Calvo, T. (ed.) (2000): Murguía e La Voz de Galicia (A Coruña: La Voz de Galicia-Biblioteca Gallega).

Murguía, M. (1896b): "Para terminar" (La Voz de Galicia, 30-IX-1896), en Calvo, T. (ed.) (2000): Murguía e La Voz de Galicia (A Coruña: La Voz de GaliciaBiblioteca Gallega). 
Murguía, M. (1896c): “Cuentas ajustadas, medio cobradas”, en Calvo, T. (ed.) (2000): Murguía e La Voz de Galicia (A Coruña: La Voz de Galicia-Biblioteca Gallega) [Orixinal publicado entre o 20-X-1896 - 27-XII-1896].

Murguía, M. (1913): "Discurso con motivo do 80 aniversario", en BRAG 73 (1-VI1913), 1-18.

Murguía, M. (1916): "Discurso pronunciado en La Fiesta de la poesia gallega. Homenaje a Rosalía Castro", en BRAG XI, 110, 26-32.

Murguía, M. (1917): "De la importante influencia que en su tiempo tuvo en Galicia la obra literaria de Rosalía", La temporada en Mondariz 8, 9 e 11.

Murguía, M. (1919): "La casa en que murió Rosalía Castro", en Calvo, T. (ed.) (2000): Murguía e La Voz de Galicia (A Coruña: La Voz de GaliciaBiblioteca Gallega).

Murguía, M. (1940) [1885]: Los precursores (Buenos Aires: Emecé EditoresColección Hórreo).

Pardo Bazán, E. (1879): "De la conversación II", en Hermida, C. (1992b): A reivindicación da Lingua Galega no Rexurdimento (1840-1891). Escolma de textos (Santiago de Compostela: Consello da Cultura Galega).

Pardo Bazán, E. (1984) [1888]: De mi tierra (Madrid: Tipografía Casa de Misericordia).

Pensado X.L. (1986): "Rosalía e a lingua galega do seu tempo e do seu entorno" en Actas do Congreso Internacional de estudios sobre Rosalía de Castro e o seu tempo. 15-20 de xullo de 1985. Vol. 3 (Santiago de Compostela: Consello da Cultura Galega-Universidade de Santiago de Compostela).

Posada, J.M. (1863): “Reseña de Cantares gallegos”, en Alonso Montero, X. (1985): En torno a Rosalía (Madrid: Ediciones Júcar).

Risco, V. (1976): Manuel Murguía (Vigo: Galaxia).

Rodríguez Sánchez, F. (1988): Análise sociolóxica da obra de Rosalía de Castro (Vigo: AS-PG).

Ruiz Aguilera, V. (1864): “Cantares gallegos. Por Rosalía Castro de Murguía”, El Museo universal VIII, 22 (29-V-1864), 173-174; 23 (5-VI-1864), 182183.

Saco Arce, X. A. (1876): “El habla gallega, ¿Es lengua, idioma o dialecto?”, El Heraldo Gallego 133 (10-IV-1876). 
Sánchez Rei, X.M. (2005): “Trazos Xerais da tradición gramatical galega”, Revista Galega de Filoloxía 6, 93-121 (A Coruña: Universidade da Coruña).

Sanmartín Rei, G. (2009): Nos camiños do entusiasmo. Calidade da lingua e planificación (Vigo: Xerais).

Saralegui y Medina, L. de (1886): Galicia y sus poetas (Ferrol: Est. Tipográfico de Ricardo Pita).

Taboada Fernández, N. (1880): "Follas Novas. Versos en gallego por Rosalía Castro de Murguía", en Alonso Montero, X. (1985): En torno a Rosalia (Madrid: Ediciones Júcar), 242-244.

Vicenti, A. (1880): "Follas Novas", en Alonso Montero, X. (1985): En torno a Rosalía (Madrid: Ediciones Júcar), 245-253. 